This document is the author's post-print version of this article, i.e. the final draft version after review. The final document is available in European Journal of Wood and Wood Products and can be viewed online by using the DOI 10.1007/s00107-015-0992-z

We also refer to this URL for citing details.

Li, W.Z., Van den Bulcke, J., De Windt, I., Dhaene, J., Van Acker, J. (2015). Moisture behavior and structural changes of plywood during outdoor exposure. European journal of Wood and Wood Products 74: 211-221. 


\section{Moisture behavior and structural changes of plywood during outdoor exposure}

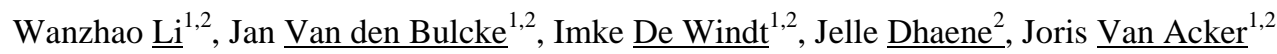

${ }^{1}$ Ghent University, Department of Forest and Water Management, Faculty of Bioscience Engineering, Coupure Links 653, 9000 Gent, Belgium, Wanzhao.Li@UGent.be

${ }^{2}$ UGCT, Department of Physics and Astronomy, University Ghent Centre for X-ray Tomography, Proeftuinstraat 86, 9000 Ghent, Belgium

\section{Abstract:}

Plywood is an important wood-based construction material yet prone to water uptake, as such potentially decreasing mechanical properties and increasing decay risk. It is, therefore, essential to understand the moisture behavior and structural changes of plywood in service. In this research, several plywood specimens were exposed in outdoor weathering conditions for approximately one year. During this period, the average moisture variation of and moisture distribution in different veneer layers of a set of plywood specimens and detailed field weather information were recorded continuously. The internal structure of the specimens was also monitored by periodically scanning using X-ray CT. Measurements indicate that moisture distribution in plywood is not homogeneous in outdoor conditions. The second layer can, in some plywood types, accumulate a significant amount of rain, and long rainy periods and cloudy weather can keep the moisture content of the inner layers of plywood significantly high. Moisture accumulation and moisture dynamics, in combination with wood species, are the main factors causing structural changes, mainly occurring as cracks, of the plywood veneers in service. The glue line between the veneers, however, is not ruptured after one year of outdoor exposure. Plywood with layers having a slow water sorption and fast water desorption could effectively avoid internal moisture accumulation and cracks in service. Based on the knowledge of the interrelationship of weather data, internal moisture behavior and structural changes in service, fit-for-purpose design of plywood could be improved and service life prediction is at hand.

Keywords: Moisture distribution; Structural change; Time of wetness (TOW); X-ray CT scanning; Plywood.

\section{Introduction:}

Plywood is a highly valued construction material which is used, more than other wood-based panels, in class 3 situations where it is subjected to natural weathering (Van Acker and De Smet 2007). However, as a 
wood based material, moisture influences its physical and mechanical properties (Drow 1957, Lee and Biblis 1976). In practice, weathering conditions with alternating wetting and drying cycles could obviously decrease the mechanical properties of plywood (River 1994). Knowledge on moisture behavior is thus essential to protect plywood panels and predict their changing properties in service. To obtain the average moisture content (MC) of wood samples and from wood derived materials, a continuous moisture measurement (CMM) set-up was developed, which can continuously weigh specimens' mass and simultaneously record the local climate (Van den Bulcke et al. 2009). Based on the data from this CMM setup, the relation between weather data and the amount of days with an average MC higher than $20 \%$ or $25 \%$ was further analyzed (Van den Bulcke et al. 2011). In addition to the average MC, other studies reported on continuously recording of the internal MC of solid wood samples by using electrical moisture measurements (Brischke et al. 2008a); decay in those monitored wood samples was further investigated as well and linked to the MC and local climate (Brischke et al. 2008b). With a similar set-up, an adapted electrical moisture measurement method was introduced by $\mathrm{Li}$ and co-workers ( $\mathrm{Li}$ et al. 2013) to measure the internal moisture in plywood. This method allows to map the moisture dynamics of the different layers of plywood, which is especially valuable for in-service testing. With the data of the moisture distribution at hand, the influence of moisture on the performance of plywood in service can be investigated better and compared to using either only the value of the average MC or only the single-point internal MC. Non-uniform moisture distribution naturally leads to non-homogeneous variation in the properties of plywood in service. Studying moisture distribution in function of local properties of plywood is therefore valuable. X-ray CT scanning has been used to investigate the internal structure and density distribution of wood materials (Chen et al. 2009, De Ridder et al. 2011, Lindgren 1991). Hence, this method is well-suited to monitor the structural changes of plywood, which is essential to understand the influence of moisture distribution on local structure and vice versa. Although plenty of research reports on plywood, limited information is available on studying layer based properties of plywood in service (Antikainen et al. 2015, Gillespie and River 1976, Kojima and Suzuki 2011a, Kojima and Suzuki 2011b, Reinprecht and Kmet'ova 2014).

The objective of this paper is to highlight the moisture behavior, i.e. average moisture variation and moisture distribution, as well as structural changes of plywood specimens in outdoor weathering conditions. The specimens were subjected to two different exposure conditions for approximately one year. Weather 
data was also recorded using a weather station consisting of a solar radiation sensor, a tipping bucket rain gauge, a relative humidity probe and a thermometer. According to the results obtained with the techniques above, i.e. weather data logging, average moisture variation, moisture distribution mapping and mapping of structural changes, the relationship between weathering, moisture behavior and structural changes of plywood panels in service was analyzed.

\section{Method and Materials:}

\subsection{Preparation of the specimens}

Specimens were prepared from uncoated plywood panels produced by European plywood companies. Two specimens from each plywood panel (Table 1) were cut to the size of $100 \times 100 \times$ panel thickness $\mathrm{mm}^{3}$. In order to investigate the detailed performance of specimens, limited plywood types were used. All side edges of the specimens were sealed with a two component acrylic polyurethane sealant. Electrodes were carefully installed in the different layers of the specimens to monitor the MC of these layers (Table 1) according to the method described in Li et al. (2013). Afterwards, all specimens were conditioned at $65 \%$ relative humidity (RH) and $20{ }^{\circ} \mathrm{C}$ until constant mass prior to outdoor exposure on the CMM set-up as described in Van den Bulcke et al. (2009). Specimens were put in two different exposure conditions on the CMM set-up to sheltered and non-sheltered situations. More specifically one set of specimens was covered with a textile sheet supported by two transparent glass walls on south and north side with the surface of the specimens facing north while another set of specimens was not covered facing south (Fig.1). Approximately 25\% of rainfall and $25 \%$ of solar radiation could penetrate the cover used to shade the specimens. All specimens were installed at an angle of $45^{\circ}$. Adjacent to the CMM set-up, a weather station recorded precipitation (mm), relative humidity $(\%)$, solar radiation $\left(\mathrm{W} / \mathrm{m}^{2}\right)$ and temperature $\left({ }^{\circ} \mathrm{C}\right)$. Electrical data loggers (Materialfox mini), all programmed with the same formula to convert electrical resistance to $\mathrm{MC}$, were used to record the MC of all specimens. The electrical MC data was not corrected considering that the three wood are more or less similar and species correction is usually less than 2 percent (James 1988). For other wood species, however, this could be different. The measurements started on $29^{\text {th }}$ October 2013 with recordings of weather data and CMM weighing every $5 \mathrm{~min}$, whereas electrical MC was measured every $10 \mathrm{~min}$. The default minimum value of electrical MC measurement data logger is $11 \%$. This study contains the data of approximately one 
year of outdoor exposure. Missing data, because of periodically removal of the specimens for scanning or due to temporary power failure, were excluded from the analysis.

Table 1

Plywood type, structure and position of electrodes (exposed face of the specimen $=1^{\text {st }}$ veneer).

\begin{tabular}{cccccccc}
\hline Code & $\begin{array}{c}\text { Wood } \\
\text { species }\end{array}$ & Glue & $\begin{array}{c}\text { \# of } \\
\text { plies }\end{array}$ & $\begin{array}{c}\text { Veneers } \\
(\mathrm{mm})\end{array}$ & $\begin{array}{c}\text { Thickness } \\
(\mathrm{mm})\end{array}$ & $\begin{array}{c}\text { Oven dry density } \\
\left(\mathrm{Kg} / \mathrm{m}^{3}\right)\end{array}$ & $\begin{array}{c}\text { Electrodes } \\
(\text { veneer number })\end{array}$ \\
\hline P1 & poplar & UMF & 7 & $1.0 / 2.6 / 2.6$ & 14.9 & 0.34 & $2^{\text {nd }}, 3^{\text {rd }}, 4^{\text {th }}$ \\
P2 & poplar & PF & 7 & $0.8 / 2.5 / 2.8$ & 14.5 & 0.43 & $2^{\text {nd }}, 3^{\text {rd }}, 4^{\text {th }}$ \\
B1 & birch & PF & 11 & $1.1 / 1.4 / 1.4$ & 14.8 & 0.61 & $2^{\text {nd }}, 4^{\text {th }}, 6^{\text {th }}$ \\
B2 & birch & PF & 11 & $1.5 / 1.4 / 1.4$ & 15.7 & 0.63 & $2^{\text {nd }}, 4^{\text {th }}, 6^{\text {th }}$ \\
O1 & okoumé & PF & 7 & $1.1 / 2.5 / 2.7$ & 15.1 & 0.46 & $2^{\text {nd }}, 3^{\text {rd }}, 4^{\text {th }}$ \\
\hline
\end{tabular}

PF: phenol formaldehyde glue; UMF: urea melamine formaldehyde glue.

Veneer thickness: top veneer/inner cross/ inner parallel.

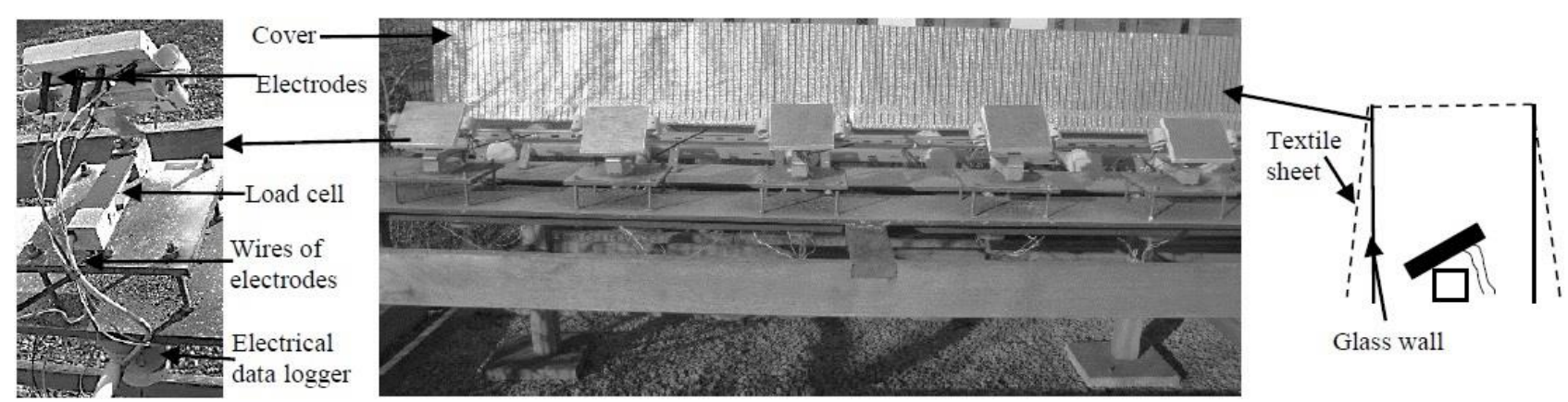

Fig.1 Set-up of the specimens in two different weathering conditions at CMM.

\section{$2.2 X$-ray CT scanning and flatbed scanning}

All specimens were periodically scanned with HECTOR (Masschaele et al. 2013), a high-energy CT scanner optimized for research, developed by the Ghent University Centre for X-ray tomography (www.ugct.ugent.be) in collaboration with the Ghent University (UGent) spin-off company XRE (www.xre.be). The approximated voxel pitch of the reconstructions was $80 \mu \mathrm{m}$. The specimens were scanned before outdoor exposure and on the $28^{\text {th }}$ of November 2013, the $5^{\text {th }}$ of February 2014, and the $5^{\text {th }}$ of June 2014 and the $4^{\text {th }}$ of October 2014. To ensure the similar conditions for all specimens, they were conditioned at $65 \% \mathrm{RH}$ and $20{ }^{\circ} \mathrm{C}$ before scanning. In addition to these periodic scans with moderate resolution, high resolution scans with an approximate voxel pitch of $20 \mu \mathrm{m}$ of a region of interest of all specimens were obtained at the end of experiment. Reconstruction was performed using the software package Octopus Reconstruction (Vlassenbroeck et al. 2007), licensed by the UGent spin-off company InsideMatters (www.insidematters.be). 
The surface of all specimens was also scanned at the same time intervals using an Epson Perfection 4990 Photo Scanner with a resolution of approximately $50 \mu \mathrm{m}$.

\subsection{CMM data processing}

In order to obtain the MC of specimens after conditioning, 6 control specimens of $50 \times 50 \times$ panel thickness $\mathrm{mm}^{3}$ for each plywood type were used (Eq.1 and Eq.2). In this experiment, the part of the wires of the electrodes close to the specimen were attached to the CMM set-up, such that both mass of the specimen and the wires was measured. Since specimens were periodically removed for scanning and it is difficult to reattach the wires at the exact same position, the average MC of specimens during exposure was calculated according to Eq.3. The influence of wind on free-hanging wires was taken into account during data analysis also.

$\mathrm{MC}_{\mathrm{c}}=\left(\mathrm{m}_{\mathrm{c}}-\mathrm{m}_{\mathrm{d}}\right) / \mathrm{m}_{\mathrm{d}}$

with $\mathrm{MC}_{\mathrm{c}}$ : the moisture content of control specimen after conditioning $(\%) ; \mathrm{m}_{\mathrm{c}}$ : mass of the control specimen after conditioning $(\mathrm{g}) ; \mathrm{m}_{\mathrm{d}}$ : oven dry mass of the control specimen $(\mathrm{g})$.

$\mathrm{m}_{1}=\mathrm{m} /\left(1+\mathrm{MC}_{\mathrm{c}}\right)$

with $\mathrm{m}_{1}$ : oven dry mass of the specimen $(\mathrm{g})$; $\mathrm{m}$ : mass of the specimen after conditioning $(\mathrm{g})$;

$\mathrm{MC}_{\mathrm{i}}=\mathrm{MC}_{\mathrm{c}}+\left(\mathrm{m}_{\mathrm{i}}-\mathrm{m}_{0}\right) / \mathrm{m}_{1}$

with $\mathrm{MC}_{\mathrm{i}}$ : the average moisture content at time $\mathrm{i}(\%) ; \mathrm{m}_{\mathrm{i}}$ : the mass of the specimen and wires at time $\mathrm{i} ; \mathrm{m}_{0}$ : the initial mass of specimen $(\mathrm{g})$.

\section{Results and Discussion:}

\subsection{Specific moisture behavior of specimens}

The original 10 min electrical MC data and 5 min CMM data were converted to daily means by averaging as presented in Fig.2 and Fig.3. Specifically, precipitation and other weather data were recalculated by summing and averaging respectively. The moisture distribution between veneer layers is not always homogenous during weathering (Fig.2 and Fig.3). The moisture sorption and desorption is faster in the outer layers, as seen for P2 during the period of the $25^{\text {th }}$ of December 2013 to the $6^{\text {th }}$ of January 2014 highlighted 
with an arrow in Fig.2. Both the average MC and MC in the inner layers of specimens, in general, is quite high from the $7^{\text {th }}$ to the $27^{\text {th }}$ of November 2013, which could be due to the cool and wet weather. During this period, heavy rainfall was registered nearly every day while temperature and solar radiation were approximately $10^{\circ} \mathrm{C}$ and $30 \mathrm{~W} / \mathrm{m}^{2}$ respectively (Fig.2 weather data), which can induce water accumulation in specimens. Periods, such as the end of July 2014, without significant rainfall and high temperature combined with a high amount of solar radiation dry the specimens and decrease their MC. The MC in the second layer and fourth layer of P2 under cover between the $21^{\text {st }}$ and the $31^{\text {st }}$ of March 2014 is as high as $26 \%$ (Fig. 2 arrow b). Heavy rainfall $(9.8 \mathrm{~mm})$ on the $21^{\text {st }}$ of March 2014 and slow moisture desorption in covered condition could be the cause of such high moisture content. Compared to the second and the fourth layer, the MC of the third layer of P2 under cover is lower. Possibly water accumulated mainly between the electrodes of these two layers, given the fact that the overall average MC is not significantly high. This could be a result from the position of the electrodes in layer P2 under cover, i.e. electrodes of the second and fourth layer are at the side close to the edge facing precipitation and the electrodes of the third layer are at the other side. Small amounts of water penetrating from above thus possibly induced an increased MC in the second and fourth layers of P2 under cover. The MC of the second layer of B2 between the $3^{\text {rd }}$ and the $7^{\text {th }}$ of March 2014 is also pronounced (arrow c in Fig. 3). Probably the electrical current, following the path of minimal resistance, could cross the glue line and flow along the top layer that was saturated with water after raining.

\subsubsection{Relationship between average MC and moisture distribution of specimens in service}

The influence of rainfall events on moisture dynamics in specimens is clearly distinguishable. Almost each rainfall event causes an average MC increase and a similar result was obtained by Van den Bulcke et al. (2009). Compared to the average MC, the MC of the inner layers is also related to rainfall events but does not increase after each rain event, given that during a rainfall event water mainly accumulates in the outer layers and evaporates afterwards. Only heavy rainfall can result in an increase in the MC of the inner layers of all test specimens. The peak of MC in the inner layers (dashed arrow d) appears later than the peak of average MC (solid arrow d) after raining at the start of the exposure period (Fig.3 B2 under cover), due to the slower process of water diffusion. This lag effect becomes small when exposure time increases, which could be caused by structure changes, i.e. crack formation, increasing the speed of water movement into specimens. 

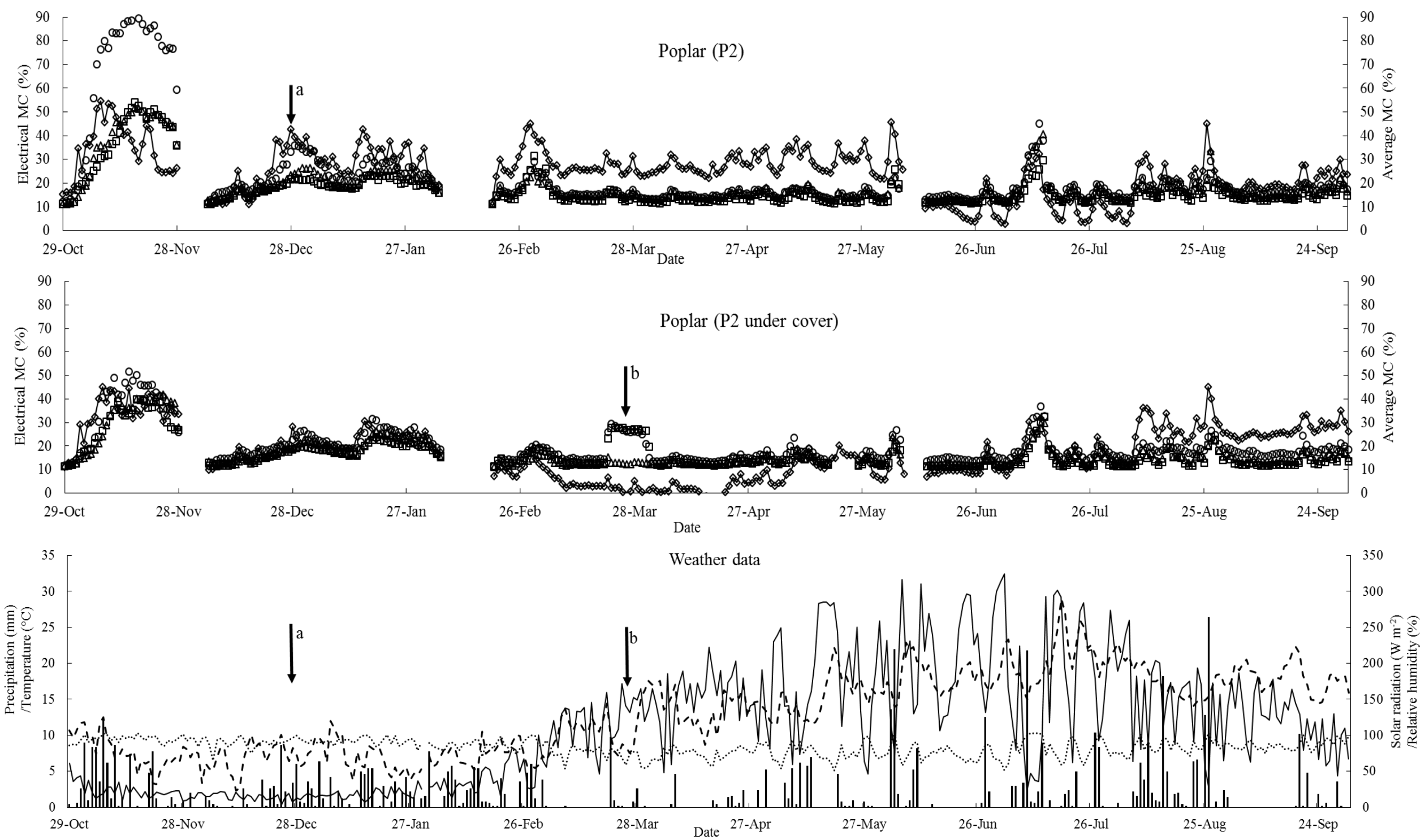

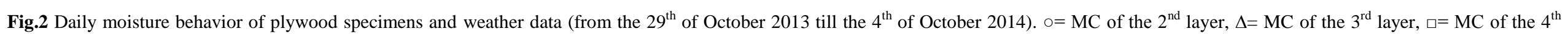
layer, $\diamond=$ average MC of specimens. Weather data: bar graph= precipitation, solid line $=$ solar radiation, dashed line $=$ temperature, dotted line $=$ relative humidity. 

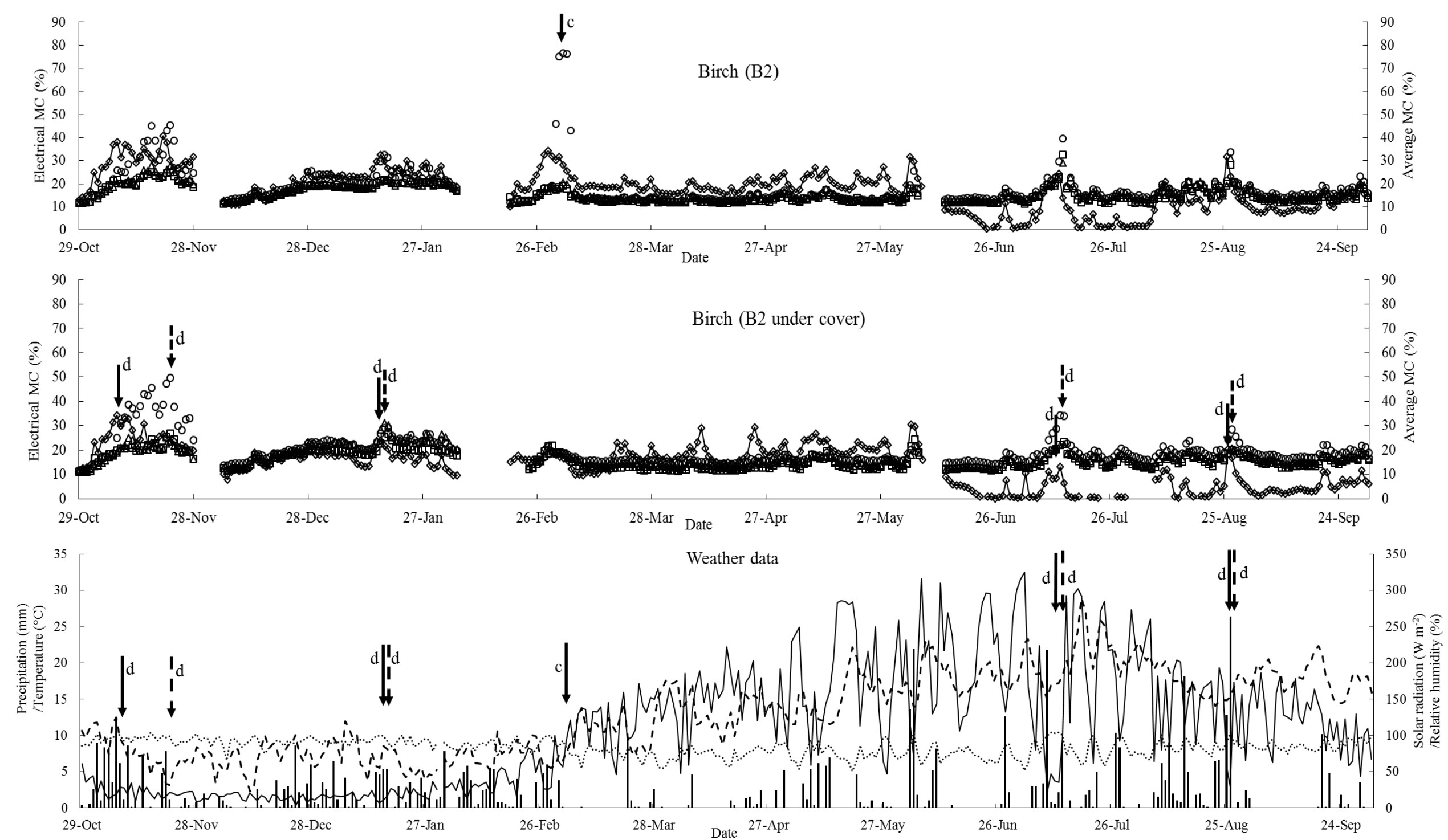

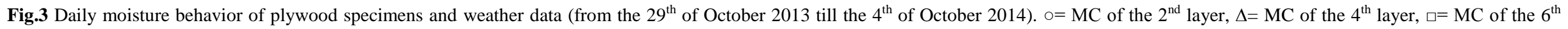
layer, $\diamond=$ average MC specimens. Weather data: bar graph= precipitation, solid line $=$ solar radiation, dashed line $=$ temperature, dotted line $=$ relative humidity . 


\subsubsection{Moisture behavior in different exposure conditions}

Specimens were subjected to two different exposure conditions, i.e. under cover and uncovered. The cover, partially protecting the specimens from rainfall, solar radiation and wind, is comparable to a partial shelter in practice. The influence of the cover on moisture distribution in the inner layers of the specimens is well correlated with average MC (Fig.2 and Fig.3). Both the average MC and inner MC of sheltered specimens is, in general, lower since part of the precipitated water is blocked by the sheet used to cover the specimens. There is, however, one exception. During the last 100 days of exposure (July, August and September of 2014), the average MC in uncovered P2 is slightly lower than in P2 under cover. It is possibly because water desorption is faster due to higher temperature and stronger solar radiation for the uncovered sample. The influence of a cover on the moisture dynamics of P2 is larger compared with B2. Poplar porosity is rather high, as such acting as a strong capillary reservoir of water. A rather large amount of water, therefore, is needed to saturate the poplar plywood specimens. Since the cover decreases the amount of precipitation, it has a significant influence on moisture dynamics of P2. Compared to B2, a larger amount of water and shorter sorption time is required for P2 when water reaches the inner layers as reported in Li et al. (2014) investigating moisture distribution on the same batch of specimens using neutron radiography. The cover decreases the amount of water absorbed by the specimen. Simultaneously, since solar radiation is reduced this results in slower water evaporation and thus longer wetting time. The cover, therefore, could have a larger influence on the MC in the inner layers of P2 than B2. This hypothesis is consistent with the results in Fig.2 and Fig.3. Specifically, the MC of the inner layers of P2 under cover is obviously smaller than P2 especially in the beginning of the exposure. The MC in the inner layers of uncovered B2 and B2 under cover are similar. This proves that the impact of a cover on the moisture behavior is different for different plywood types. This difference is mainly determined by plywood characteristics, e.g. wood species and glue line. During March and April of 2014, a low average MC and default minimum electrical MC of P2 under cover could be caused by water evaporation (solar radiation) in combination with only little water absorption.

\subsubsection{Influence of weathering on the moisture distribution of specimens}

The internal MC of specimens increased due to intensive rainfall events, however, the increase is not only concordant with the amount of precipitation (Fig.2 and Fig.3). This phenomenon is studied in detail by 
selecting two periods (from the $9^{\text {th }}$ to the $14^{\text {th }}$ of July 2014 and from the $24^{\text {th }}$ to the $29^{\text {th }}$ of August 2014). The amount of precipitation during these two periods is $34.4 \mathrm{~mm}$ and $40.0 \mathrm{~mm}$ respectively. The hourly MC and weather data were calculated and shown in Fig.4. The inner layers of the specimens had an increased MC for a longer time in the first period compared to the second period, although a smaller total amount of precipitation is recorded (Fig.4). This difference is caused by dissimilar weathering conditions. The weather in the first period is cloudier with continuous rain and low solar radiation for most of the time. More water is absorbed when there is almost continuous rainfall, and in combination with low solar radiation, and thus low water evaporation, this increases the MC. In the second period, several separate heavy rainfall events were registered which caused an obvious increase in MC even in the inner layers of the specimens. The moisture, however, could quickly evaporate because of intensive solar radiation after rain. The short and noncontinuous rain and cloudless weather could thus hardly increase the MC of the inner layers of the specimens. Similar results were obtained on average MC of plywood in weathering by Van den Bulcke et al. (2009), which could be well explained by the moisture distribution obtained in this experiment. The MC of the inner layers generally starts to decrease (arrow in Fig.4) when solar radiation and temperature reach a maximum. The MC is significantly high when rainfall events occur in the evening of the day before since low temperatures and only limited solar radiation result in higher MC. High temperature and intense solar radiation thus are the main reasons of moisture desorption in weathering condition. When taking a closer look at the cyclic MC in the second layer, it correlates with the alternation of day and night without heavy precipitation. Specifically, the MC starts to decrease because of diurnal solar radiation and reaches a minimum around midnight. Afterwards, the MC increases, possibly due to the condensation during the night. This phenomenon is not clear in the third and fourth layer that are less sensitive to such influences. Rainfall distribution thus does have a rather substantial influence on moisture accumulation in the inner layers of plywood. Temperature and solar radiation as well as day and night alternation also have an influence on the short-term moisture dynamics of the inner layers of plywood. 

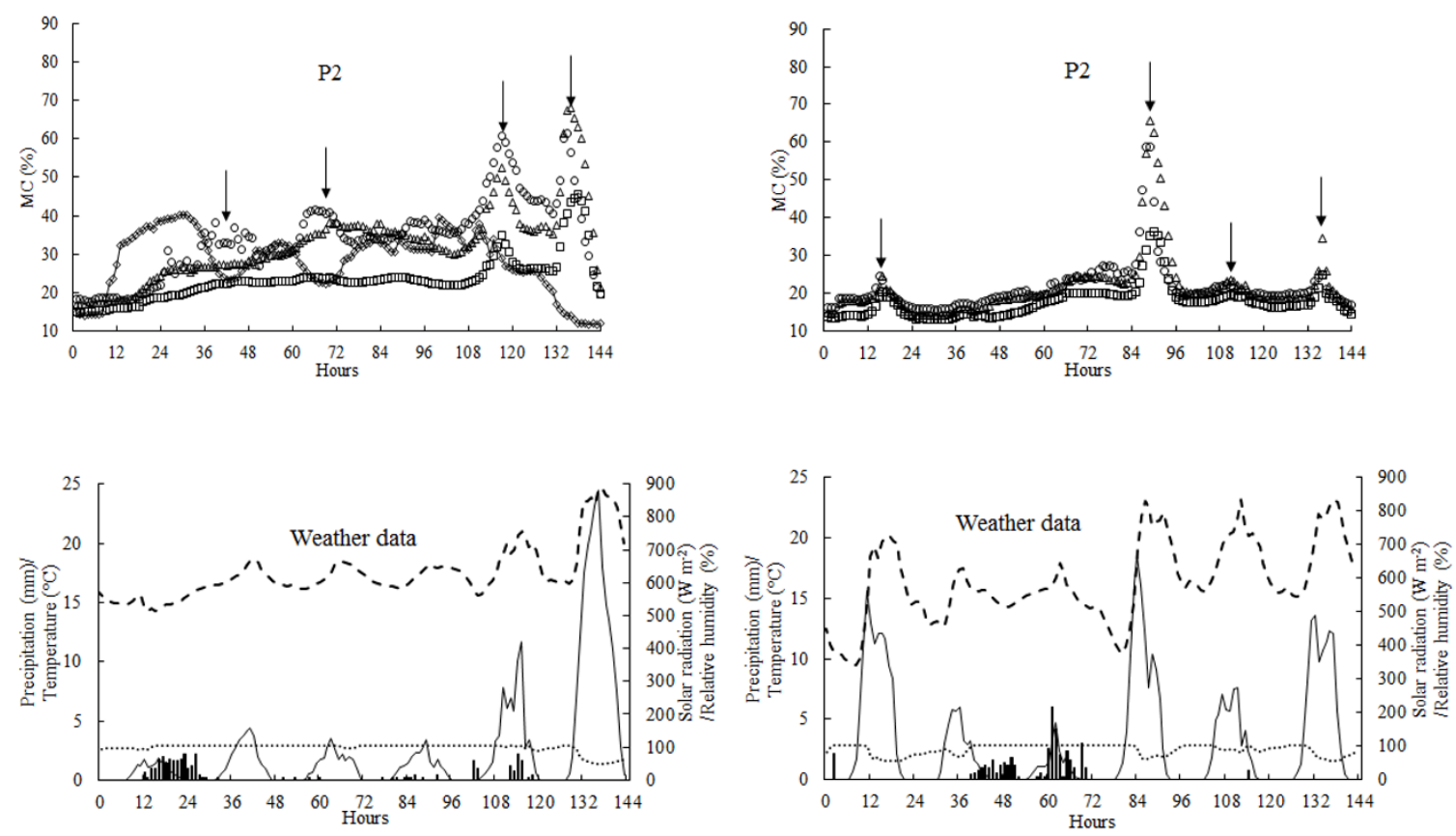

Fig.4 Hourly MC and weather data from the $9^{\text {th }}$ to the $14^{\text {th }}$ of July 2014 in the left column and from the $24^{\text {th }}$ to the $29^{\text {th }}$ of August 2014 in the right column. $\triangle=\mathrm{MC}$ of the $2^{\text {nd }}$ layer, $\Delta=\mathrm{MC}$ of the $3^{\text {rd }}$ layer, $\square=\mathrm{MC}$ of the $4^{\text {th }}$ layer, bar graph= precipitation, solid line $=$ solar radiation, dashed line $=$ temperature, dotted line $=$ relative humidity.

\subsection{Relationship between moisture distribution and plywood characteristics}

Temperature and moisture are the most important factors for fungal growth in wood based materials (Viitanen 1997). Generally, the MC threshold for decay is influenced by wood and fungal species as well as the type of wood treatment (Meyer and Brischke 2015). In this research, 20\% MC was used as the reference value for calculation of time of wetness (TOW) in different layers of the exposed plywood panels.

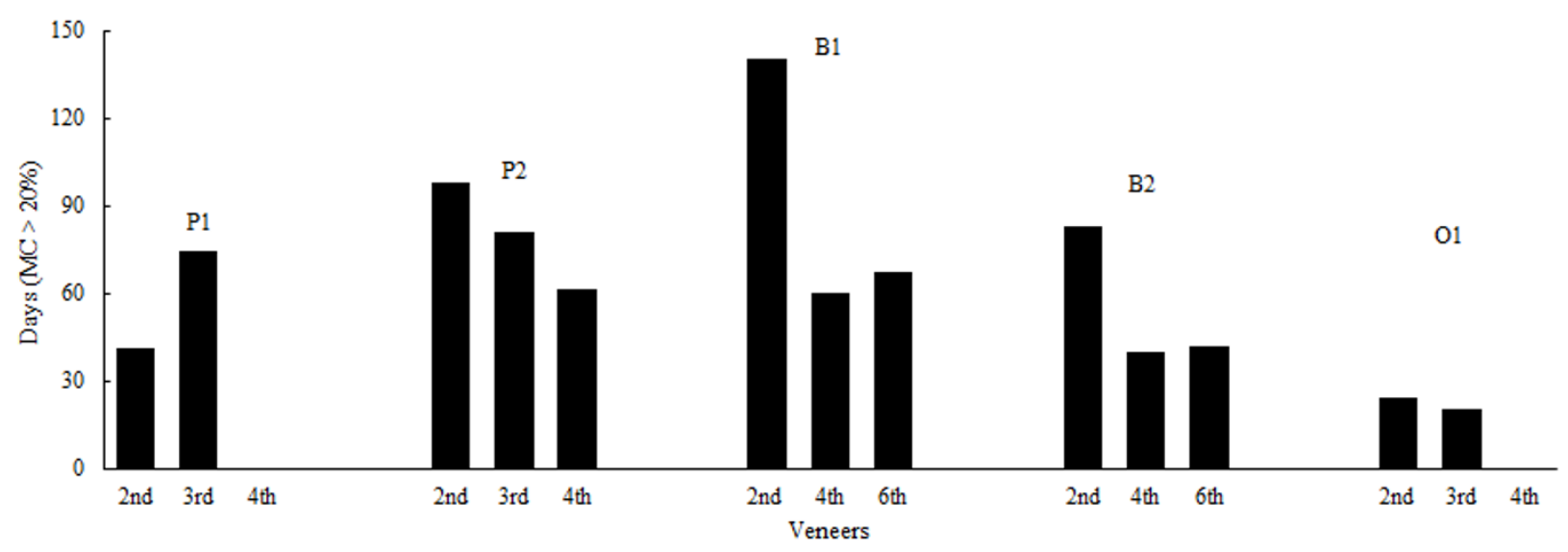

Fig.5 Amount of days with an MC higher than 20\% (TOW) in different layers of the specimens.

Moisture accumulated for most of the specimens in the second layer causing a high TOW (Fig.5). For P1 with UMF glue, however, most of the water accumulated in the third layer, which is possibly because water 
penetrate partially via the voids of the drilled holes, which were not entirely filled with isolating glue, to the region between the electrodes of the third layer of P1 as such causing a high MC. The TOW in each layer of $\mathrm{P} 1$ is smaller compared to $\mathrm{P} 2$, which means UMF could efficiently protect plywood from water penetration. This result is consistent with the results obtained with neutron radiography and standard laboratory absorption testing ( $\mathrm{Li}$ et al. 2014).

Compared with the TOW of poplar (P) and birch plywood (B), the TOW of okoumé plywood $(\mathrm{O})$ is much lower. Consequently, okoumé, a wood species with high water resistance, could be effectively used as water barrier although low durability. The PF glue used in $\mathrm{O} 1$ also allowed a high moisture desorption rate. Thus plywood similar in behavior to $\mathrm{O} 1$ could be suitable for outdoor application.

B1 is identical to B2, except the latter has a thicker top veneer. Fig.5 illustrates that the TOW in the inner layers of B1 is larger than in the inner layers of B2. Investigating the distribution of days with MC higher than $20 \%$ shows that, compared to $\mathrm{B} 1$, the lag of moisture accumulation in the monitored layers of $\mathrm{B} 2$ occurred before the $6^{\text {th }}$ of March 2014 (Fig.6). This difference could be explained by the top layer acting as a water reservoir. More water and a longer wetting time is needed for the moisture to cross the top layer and to reach the second layer. During this period, the TOW of the monitored layers in B1 and B2 is similar, which indicates that a thicker top veneer in B2 cannot effectively prevent the inner layers from water uptake. The higher TOW of B1 in the last exposure period (after the $1^{\text {st }}$ of May 2014) could be the result of a structural change of the top veneer. Fig.7 shows that compared to B2, the cracks in B1 are wider and closer to the glue line. Hence, water can easily reach the glue line and penetrate to the next layer, which induces a higher TOW in the inner layers of B1. 


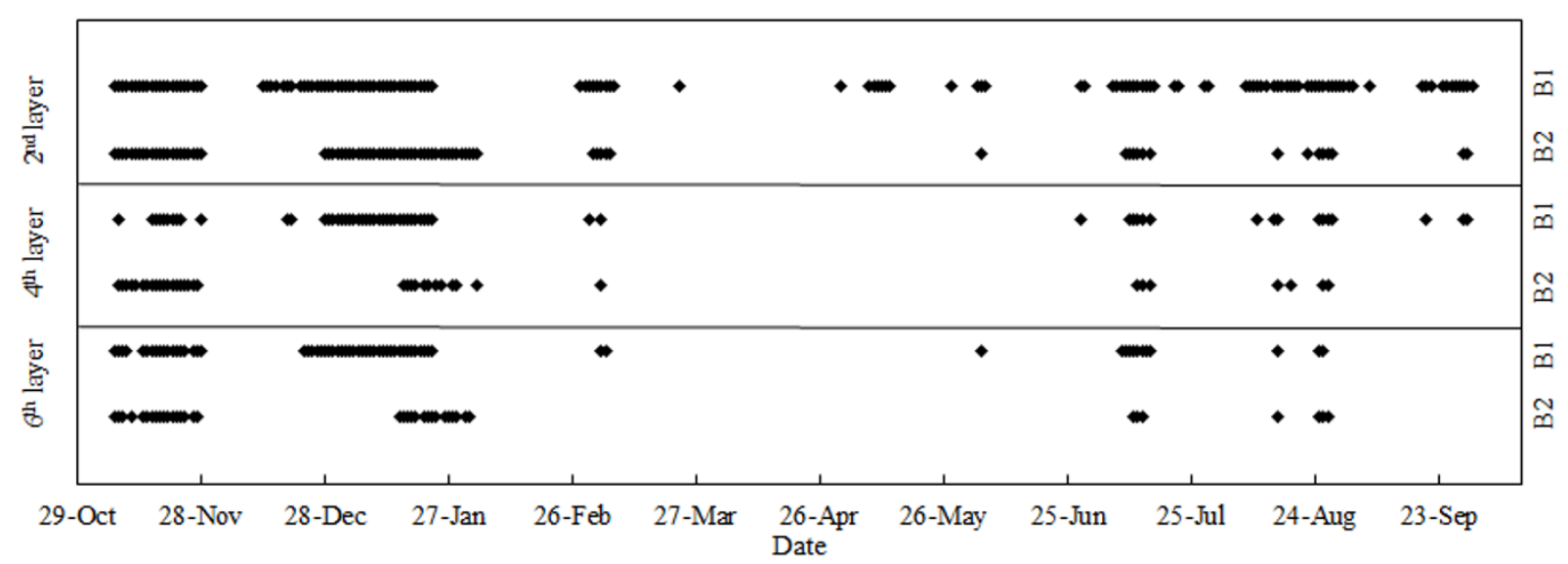

Fig.6 Days with MC higher than 20\% (TOW) in the different layers of B1 and B2.

B1

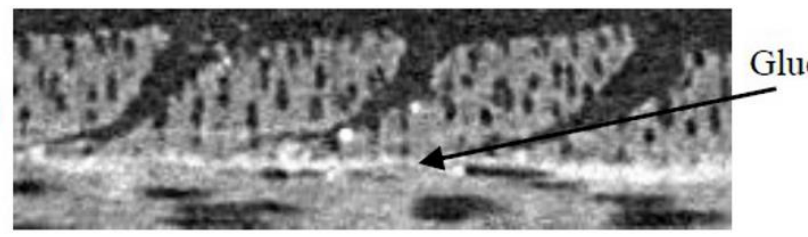
Glue line

B2

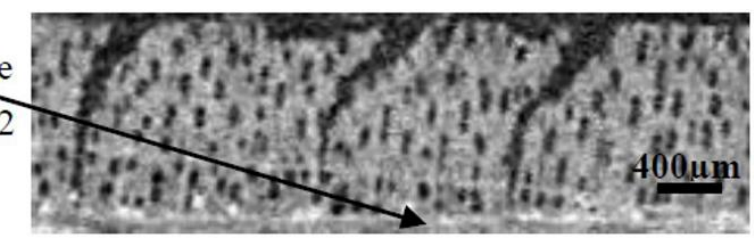

Fig.7 Structure of the top veneers (top layer in the images) of B1 and B2 after approximately one year exposure obtained from X-ray CT scanning with high resolution.

\subsection{Structural changes of specimens during weathering}

\subsubsection{Surface appearance of the specimens}

The surface of the specimens clearly changed as function of exposure time. The most apparent changes are cracking and darkening (Fig.8).

Cyclic sorption-desorption and related swelling-shrinkage can lead to significant changes. The surface scans in Fig.8 illustrate the variation in surface appearance among wood species. Birch plywood has a high amount of rather deep cracks compared to poplar and okoumé plywood. The amount of swelling-shrinkage, generally speaking, positively relates to the density of wood (Walker 1993). In weathering conditions with repeated wetting and drying, large shape variation occurred in birch plywood due to its high density and thus significant structural changes, mainly cracks, in birch plywood appeared.

Darkening and even degradation of the surface could be induced by fungi decomposing the carbohydrates and lignin, surface oxidation, generation of new chromophoric groups and other processes described in depth 
in literature (George 1991, Hon and Feist 1986). Wood degradation in weathering is initiated primarily by solar radiation (Williams 2005). The significant amount of solar radiation in summer time (between the $5^{\text {th }}$ of June and the $4^{\text {th }}$ of October 2014) is thus an essential factor for wood discoloration and degradation shown as obvious visible changes in appearance in this period (Fig.8).

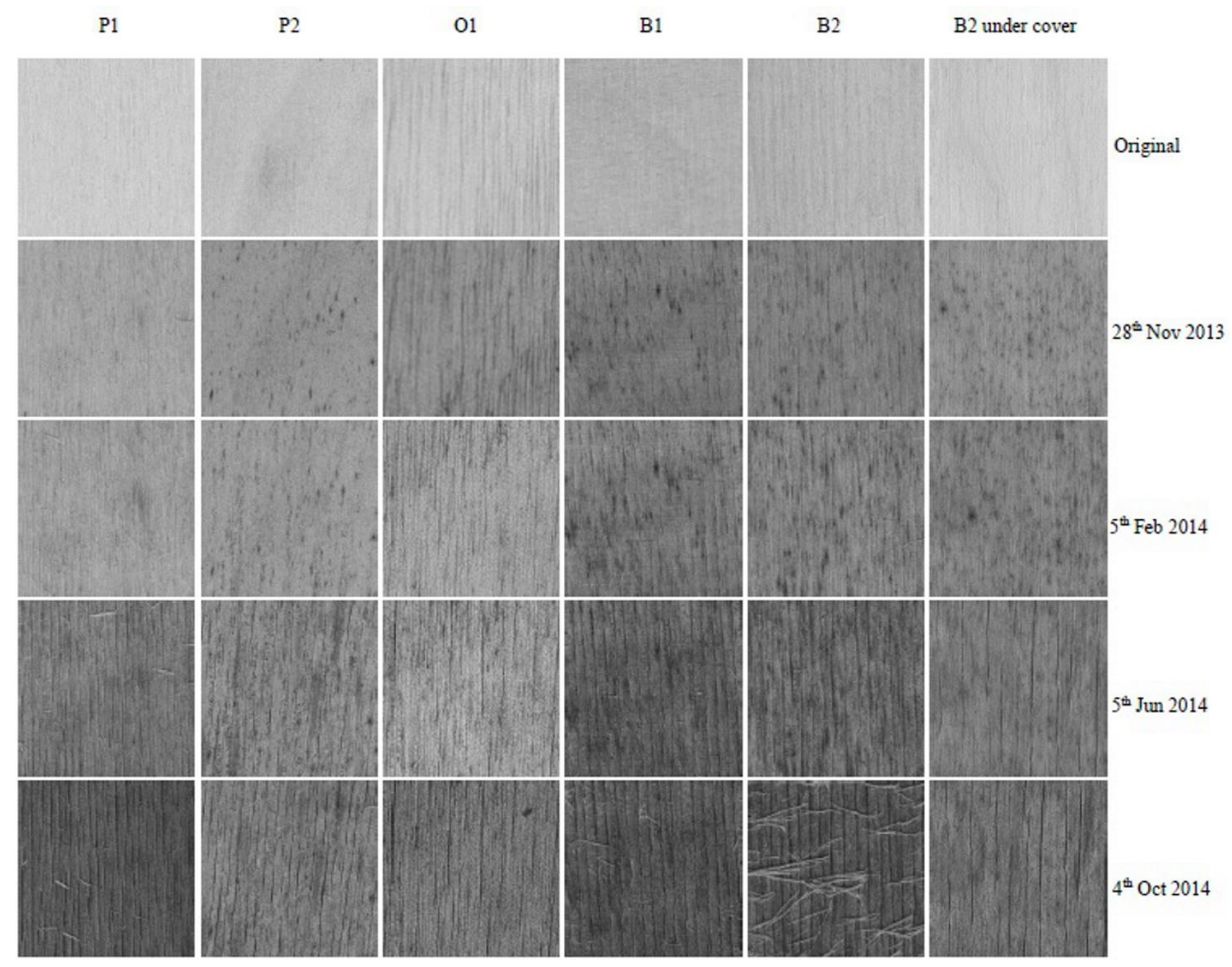

Fig.8 Surface of the specimens imaged with a flatbed scanner.

Fig.8 shows that, in general, after approximately one year exposure, the effects are much less pronounced for specimens under a cover, although the surface of B2 under cover also darkens and has cracks. Nevertheless, compared with B2 uncovered, these changes are much smaller.

\subsubsection{Changes in the veneers}

Surface discoloration and structural variations, which are visible on the surface, are used to assess the durability of wood-based products (Evans et al. 1996, Kropf et al. 1994). The internal structural changes, however, are difficult to take into account. Changes in the internal structure during long-term exposure can 
definitely influence properties. One can visualize these changes by X-ray CT scanning. P2, B1 and B2 all show distinct cracks appearing in the second layer (Fig.9). Their low water resistance even increases moisture dynamics and causes cracks in the second layers. Water can easily penetrate along veneer checks of plywood ( $\mathrm{Li}$ et al. 2014), the emerging of cracks during outdoor exposure is thus possibly due to the enlargement of veneer checks. The difference between the original scan and the scan after approximately one year is, however, small for P1 and O1. The third and fourth layer of specimens were also investigated, showing no obvious structural changes.

Original
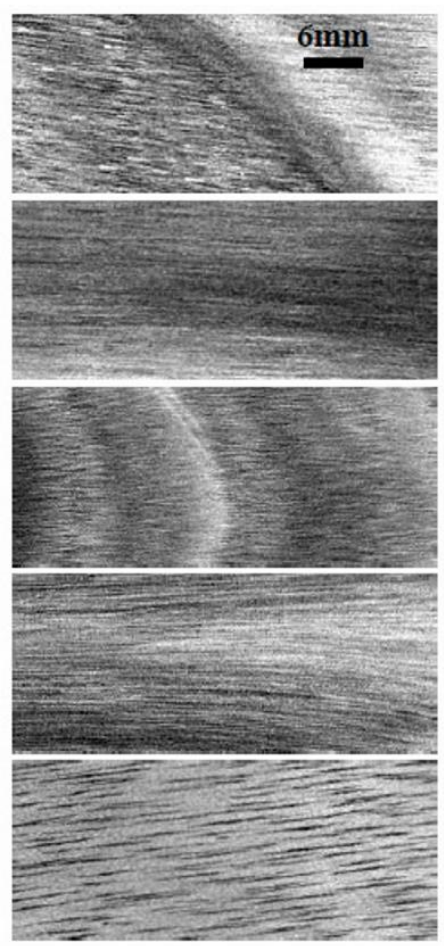

1 year
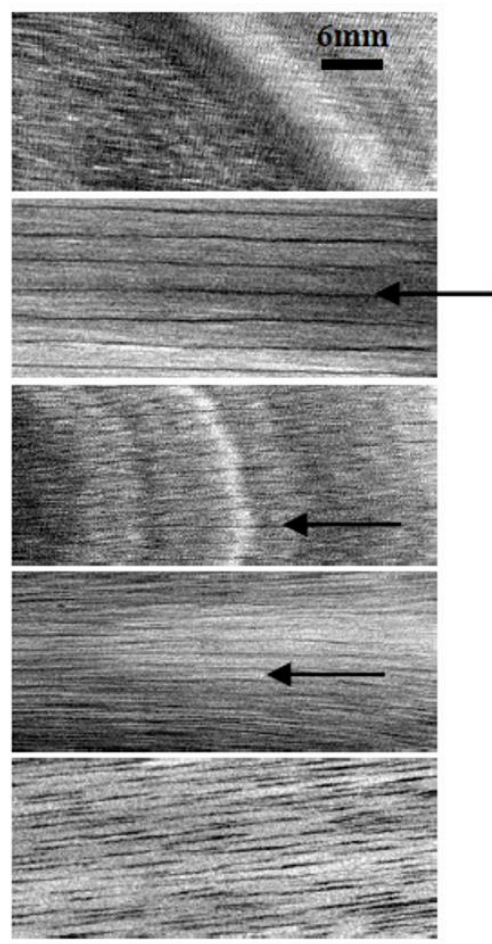

1 year

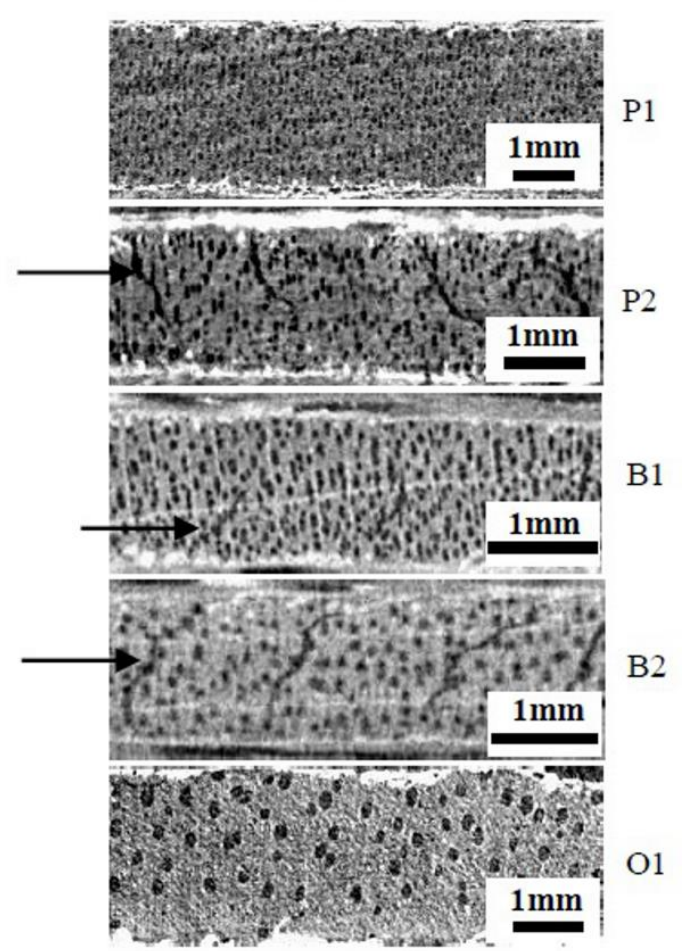

Fig.9 Horizontal cross-sections (left two columns) and vertical cross-sections (right column) of the second layer of specimens obtained with moderate resolution at periodic intervals and final high resolution X-ray CT scanning respectively.

\subsubsection{Changes in the glue line}

Compared to other wood-based materials, plywood clearly benefits from a clear and integral glue line as an effective barrier against water uptake. A durable glue line is thus essential for the performance of plywood panels in outdoor application. Fig.10 is a single slice through the plywood volume scanned with high resolution $(20 \mu \mathrm{m}) \mathrm{X}$-ray CT at the end of the experiment. Within the resolution limit, no clear rupture in the glue lines of all specimens is detected after one year of outdoor exposure. The cracks in the top layer of the specimens are clear and several severe cracks even reach the glue line (Fig.10 B1 and B2). It was 
shown that cracks also appear in the second layer of B1 and B2. These cracks, however, are not causing rupture of the glue line between them. Although cracks occurred in the veneers during weathering, the intact glue line still could act as water barrier. A strong glue line is crucial to improve the durability of plywood and can be influenced by glue type, pressing parameters and veneer wood species. These results, however, are after 1 year of exposure, yet rupture of the glue line can occur after longer exposure: Van den Bulcke et al. (2011) found cracks crossing the glue line of plywood specimens after two years of outdoor exposure in a similar outdoor climate.

P1

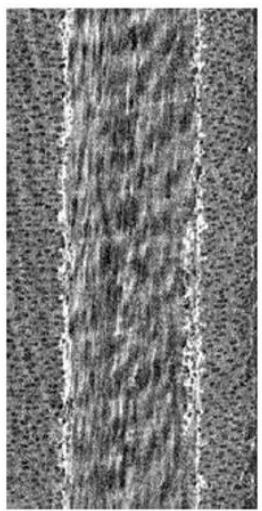

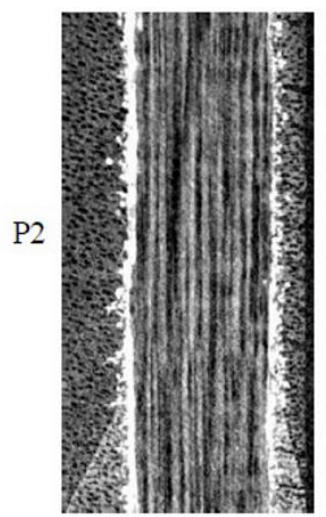
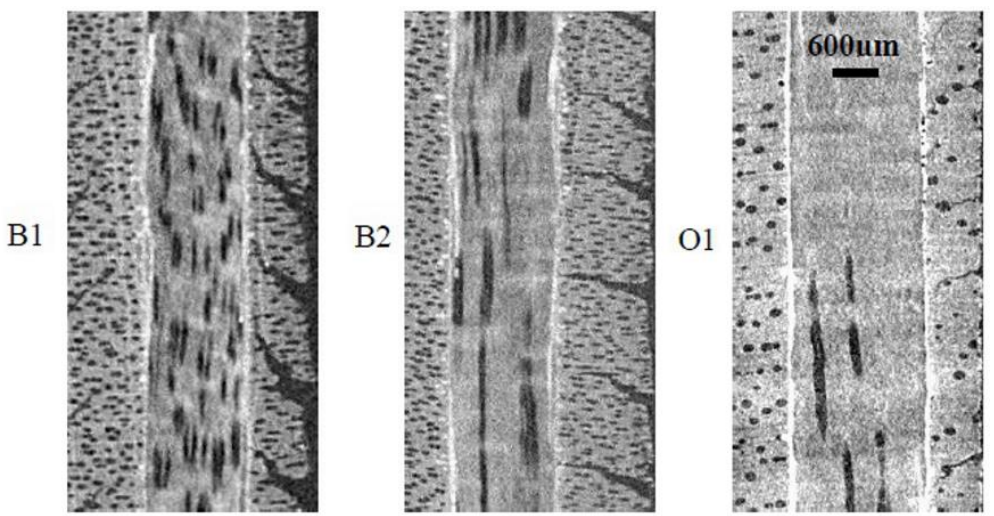

Fig.10 Detailed microstructure of the three top layers (right layer is the top layer) of the tested specimens after approximately one year outdoor exposure obtained with high resolution X-ray CT scanning.

\section{Conclusion:}

Moisture distribution in plywood specimens is not homogenous during outdoor exposure. Continuous raining, thus implying long term cloudy weather, even increases the moisture accumulation in the inner layers of the plywood specimens. High temperature and intensive solar radiation, on the other hand, are the major factors for moisture evaporation. Short-term MC changes in the second layer correlate with the alternation of day and night. In addition to weathering conditions, the characteristics of plywood specimens significantly influence the moisture accumulation in inner layers. For specimens glued with PF, the second layer is prone to water accumulation giving rise to a high time of wetness (TOW). A UMF glue line can effectively limit water uptake. Wood species absorbing only little water are key for decreasing the risk of high TOW in inner layers of plywood. Thick top veneers can lag the moisture accumulation in inner layers. After approximately one year outdoor exposure, the structural changes occur and the moisture behavior of specimens was influenced accordingly. The cracks appear in the top layer of all specimens and the second layer of specimens with low water resistance. Cracks emerging in top veneers during exposure can increase 
moisture accumulation in the inner layers. The glue lines of all specimens are not ruptured after approximately one year of exposure. Based on the above findings, plywood including layers with slow moisture sorption and fast moisture desorption could effectively avoid moisture accumulation in the inner layers. Veneers made of wood species with good water resistance could be more suitable as top veneer of plywood aiming at outdoor application. During plywood production, it is however difficult to prepare each layer with these properties. Hence, carefully preparing outer layers is the main focus. Optimizing the combination of wood species, glue line and veneer thickness is essential. In future research, it would be interesting to study the effect of water vapor diffusion, water liquid flow, and heat transfer on the electrical MC measurement method. Combining the TOW and temperature of different layers, service life prediction of plywood could be predicted. It is also important to relate the TOW with real fungal decay (mass loss) of layers. To improve service life prediction of solid wood, investigating moisture distribution is thus essential.

\section{Acknowledgement:}

The authors would like to thank Mr. Rik De Rycke, Mr. Stijn Willen and Mr. Pieter Vanderniepen for their technical assistance. The author also would like to thank the fund from the China Scholarship Council (CSC) for the PhD funding granted to the first author. This research was performed in support of the European Project SILEX “Improving sustainability of construction materials using innovative silicon-based treatment", with project number LIFE11 ENV/BE/1046 and DO-IT Houtbouw. 


\section{Reference}

Antikainen T, Rohumaa A, Hunt CG, Levirinne M, Hughes M (2015) Estimating the spread rate of urea formaldehyde adhesive on birch (Betula pendula Roth) veneer using fluorescence. European Journal of Wood and Wood Products 73: 69-75. doi: 10.1007/s00107-014-0864-y

Brischke C, Rapp AO, Bayerbach R (2008a) Measurement system for long-term recording of wood moisture content with internal conductively glued electrodes. Building and Environment 43: 1566-1574. doi: 10.1016/j.buildenv.2007.10.002

Brischke C, Rapp AO, Bayerbach R, Morsing N, Fynholm P, Welzbacher CR (2008b) Monitoring the "material climate" of wood to predict the potential for decay: Results from in situ measurements on buildings. Building and Environment 43: 1575-1582. doi:10.1016/j.buildenv.2007.10.001

Chen S, Liu X, Fang L, Wellwood R (2009) Digital X-ray analysis of density distribution characteristics of wood-based panels. Wood Science and Technology 44: 85-93. doi:10.1007/s00226-009-0256-3

De Ridder M, Van den Bulcke J, Vansteenkiste D, Van Loo D, Dierick M, Masschaele B, De Witte Y, Mannes D, Lehmann E, Beeckman H, Van Hoorebeke L,Van Acker J (2011) High-resolution proxies for wood density variations in Terminalia superba. Annuals of Botany 107: 293-302. doi:10.1093/aob/mcq224 Evans PD, Thay PD, Schmalzl KJ (1996) Degradation of wood surfaces during natural weathering. Effects on lignin and cellulose and on the adhesion of acrylic latex primers. Wood Science and Technology 30: 411422.

George T (1991) Science and technology of wood: structure, properties, utilization. Van Nostrand Reinhold, Now York

Gillespie RH, River BH (1976) Durability of Adhesives in Plywood. Forest Products Journal 26: 21-25.

Hon DNS, Feist WC (1986) Weathering Characteristics of Hardwood Surfaces. Wood Science and Technology 20: 169-183.

James WL (1988) Electric moisture meters for wood. Dept. of Agriculture, Forest Service, Forest Products Laboratory.

Kojima Y, Suzuki S (2011a) Evaluating the durability of wood-based panels using internal bond strength results from accelerated aging treatments. Journal of Wood Science 57: 7-13. doi:10.1007/s10086-010-11314 
Kojima Y, Suzuki S (2011b) Evaluation of wood-based panel durability using bending properties after accelerated aging treatments. Journal of Wood Science 57: 126-133. doi:10.1007/s10086-010-1146-x Kropf FW, Sell J, Feist WC (1994) Comparative Weathering Tests of North-American and European Exterior Wood Finishes. Forest Products Journal 44: 33-41.

Lee WC, Biblis EJ (1976) Hygroscopic Properties and Shrinkage of Southern Yellow Pine Plywood. Wood and Fiber 8: 152-158.

Li WZ, Van den Bulcke J, De Windt I, Van Loo D, Dierick M, Brabant L,Van Acker J (2013) Combining electrical resistance and 3-D X-ray computed tomography for moisture distribution measurements in wood products exposed in dynamic moisture conditions. Building and Environment 67: 250-259. doi:10.1016/j.buildenv.2013.05.026

Li WZ, Van den Bulcke J, Mannes D, Lehmann E, De Windt I, Dierick M,Van Acker J (2014) Impact of internal structure on water-resistance of plywood studied using neutron radiography and X-ray tomography. Construction and Building Materials 73: 171-179. doi: 10.1016/j.conbuildmat.2014.09.095

Lindgren LO (1991) Medical Cat-Scanning - X-Ray Absorption-Coefficients, Ct-Numbers and Their Relation to Wood Density. Wood Science and Technology 25: 341-349.

Meyer L, Brischke C (2015) Interpretation of moisture monitoring data - Relevance of moisture content thresholds for fungal decay. The $46^{\text {th }}$ Annual meeting of the International Research Group on Wood Protection. Viña del Mar Chile

Reinprecht L, Kmet'ova L (2014) Fungal resistance and physical-mechanical properties of beech plywood having durable veneers or fungicides in surfaces. European Journal of Wood and Wood Products 72: 433443. doi:10.1007/s00107-014-0788-6

River BH (1994) Outdoor Aging of Wood-Based Panels and Correlation with Laboratory Aging. Forest Products Journal 44: 55-65.

Van den Bulcke J, De Windt I, Defoirdt N, De Smet J, Van Acker J (2011) Moisture dynamics and fungal susceptibility of plywood. International Biodeterioration \& Biodegradation 65: 708-716. doi:10.1016/j.ibiod.2010.12.015

Van den Bulcke J, Van Acker J, De Smet J (2009) An experimental set-up for real-time continuous moisture measurements of plywood exposed to outdoor climate. Building and Environment 44: 2368-2377. doi: 10.1016/j.buildenv.2009.03.021 
Viitanen HA (1997) Modelling the time factor in the development of brown rot decay in pine and spruce sapwood - The effect of critical humidity and temperature conditions. Holzforschung 51: 99-106. doi:10.1515/hfsg.1997.51.2.99

Vlassenbroeck J, Dierick M, Masschaele B, Cnudde V, Van Hoorebeke L, Jacobs P (2007) Software tools for quantification of X-ray microtomography at the UGCT. Nuclear Instruments and Methods in Physics Research Section A: Accelerators, Spectrometers, Detectors and Associated Equipment 580: 442-445. doi:10.1016/j.nima.2007.05.073

Walker JCF (1993) Primary wood processing : principles and practice. Chapman \& Hall, London; New York Williams SS (2005) 7 Weathering of Wood. Handbook of wood chemistry and wood composites. 
